\title{
Kainic Acid, NMDA and Bicuculline Induce Elevation in Concentrations of Glutathione and Amino Acids in Vivo: Biomarkers for Seizure Predisposition?
}

\author{
Abdul-Karim Abbas \\ Institute of Neuroscience and Physiology, University of Gothenburg, Gothenburg, Sweden \\ Email: Abdul-karim.abbas@neuro.gu.se \\ Received 22 February 2015; accepted 2 May 2015; published 5 May 2015 \\ Copyright (C) 2015 by author and Scientific Research Publishing Inc. \\ This work is licensed under the Creative Commons Attribution International License (CC BY). \\ http://creativecommons.org/licenses/by/4.0/ \\ (c) (i) Open Access
}

\section{Abstract}

The present study was carried out to investigate the effect of NMDA, bicuculline and kainic acid (KA) on the extracellular concentration of glutathione, phosphoethanolamine (PEA) and taurine in rat hippocampus in vivo. Rats were implanted with intrahippocampal microelectrodes perfused with free-glucose Krebs-Ringer solution and allowed to recover for about $2 \mathrm{~h}$. After assaying baseline concentrations of amino acids, NMDA or bicuculline was administered intrahippocampally, whereas KA was given systemically. Either treatment resulted in significant high extracellular concentrations of glutathione, but only NMDA or KA resulted in high concentrations of PEA and taurine. Interestingly, the increase in glutathione concentration due to KA was followed by a delayed increase of glutamate and PEA. Our results demonstrated that increased efflux of glutathione, a common consequence of different neuroexcitotoxic agents, occurs in vivo. Given that the agents used in the present study were also convulsunts, the implication of the findings on seizure predisposition was also considered.

\section{Keywords}

NMDA, Glutathione, Taurine, Hippocampus, Microdialysis, Kainic Acid, Seizure

\section{Introduction}

Glutathione, a tripeptide of glutamate, cysteine and glycine, displays high intracellular concentrations [1] [2]. This high concentration can be related to its functions in maintaining the overall reduction-oxidation potential states of neural cells [2] and protecting them against oxidative damage [3] [4]. Apart from the well-characterized 
functions in all cell types, much evidence shows that its extracellular [5] and/or intracellular [6] pool might also act, in the brain, as a neurotransmitter/neuromodulator via different mechanisms [7] like enhancement of NMDA receptors function and contribution in synaptic plasticity such as LTP [8] [9].

Moreover, there is considerable evidence that oxidative stress occurs as a consequence of prolonged seizures and may contribute to the generation of the epileptic state [10] [11]. A generalized underlying mechanism for these acute and chronic neurological diseases may be partly mediated by oxidative stress caused by overactivation of glutamate receptors [12].

Taurine is considered to have osmoregulatory [13], antioxidant [14], and neuromodulatory [15] effects, which render it to serve as endogenous anticonvulsant [14]. Moreover, phosphoethanolamine (PEA) release has been shown to be associated with several neurological disorders such as hypoglycemia, ischemia as well as epilepsy in vivo [16] [17] and in vitro [18].

In earlier studies, we found marked increase in the extracellular concentrations of glutathione, taurine and PEA in acute hippocampal slices [19] and in organotypic slices cultures [20] in response to glutamate receptor activation. Thus, the present study is a continuation of our previous research using microdialysis techniques in vivo for measuring changes in extracellular concentrations of these substances following glutamate receptor activation or the GABA receptor block and monitoring the changes in concentration during the early time window following drug application. Given that these agents are implicated in the generation of epileptiform activity and limbic seizure and that the available evidence indicates a temporal correlation between free radical generation and the development of epileptic seizures [4], the implications of our findings for these processes are also considered.

\section{Materials and Methods}

Adult male Sprague-Dawley rats, weighing 250 - 300 g were used for this study. All efforts were made to minimize animal suffering and to reduce the number of rats used. The procedures conformed to the guidelines of the Swedish Council for Laboratory Animals and were approved by the Local Ethics Committee of University of Gothenburg.

\subsection{Experimental Procedures}

Experimental procedures were conducted as described previously [17] with slight modification. Briefly, animals were anesthetized initially with isoflurane and maintained under anesthesia by i.p. injection of urethane (1.2 $\mathrm{g} / \mathrm{kg}$ ). Then, they were mounted in a stereotaxic frame. Following local anesthesia, two craniotomies were made over the parietal bone and the dialysis probe was positioned in the hippocampus (coordinates: anterior, $4.3 \mathrm{~mm}$, lateral, $2.5 \mathrm{~mm}$, from bregma, and $4.0 \mathrm{~mm}$ depth).

The dialysis probe, as developed previously [17], was perfused with oxygenated glucose-free Krebs-Ringer bicarbonate medium [21] at a flow rate of $2 \mu \mathrm{l} / \mathrm{min}$ and a steady-state period of about $2 \mathrm{~h}$ was allowed before any dialysates were collected for amino acid and peptide analysis to reach "base-line" condition. At the end of this period, perfusate fractions were collected at $20 \mathrm{~min}$ intervals resulting in $40-\mu \mathrm{l}$ volumes for each sample. The location of the probe was confirmed by visual examination of the hippocampi at the end of each experiment. The changes measured in the dialysis state are taken as an index of an altered extracellular concentration.

Drugs administration and amino acids analysis

To ensure that a stable biochemical baseline was established, samples were collected for 60 min prior to the fractions with or without acivicin (AT-125) administration $(0.2 \mathrm{mM})$, which was done for more 40 min before the drugs were either perfused via the inlet of dialysis probe or given via systemic injection. NMDA, bicuculline, a $\mathrm{GABA}_{\mathrm{A}}$ receptor antagonist, and kainic acid (KA), all purchased from Sigma (St. Louis, MO, USA), were dissolved in saline and perfused intrahippocampally to the both hippocampi (NMDA, $1 \mathrm{mM}$ and bicuculline, $100 \mu \mathrm{M}$ ) or given intraperitoneally (KA, $10-12 \mathrm{mg} / \mathrm{kg}$ ). The collected perfusates are later assayed using high-performance liquid chromatography (HPLC) and fluorescence detection after automatic precolumn derivatization with o-phthal- dialdehyde as described previously [17] [20]. The identification of amino acids in the dialysates was performed by comparison of retention times for each amino acid with that of the standard and the release of the amino acid was expressed as a percentage of the baseline period. The methodology does not discriminate between thiols and disulfides; the term glutathione therefore refers to the total concentration of reduced glutathione, glutathione dimers, and mixed glutathione disulfides [20]. 
Acivicin, donated by UpJohn (Partille, Sweden), was added to one side of hippocampus to block irreversibly the gamma-glutamyl transpeptidase (GGT) enzyme. The purpose of acivicin addition is to prevent the concealing of increased efflux of glutathione by its breakdown extracellulary, whereas its omission was intended to investigate whether a rise in the extracellular glutathione concentration might not be influenced by glutathione breakdown. Furthermore, the increase in extracellular concentration of glutamate may be due to liberation from the glutathione hydrolysis [22].

\subsection{Statistical Analysis}

All values were expressed as the means \pm SEM. All groups are analyzed using ANOVA followed by Dunnett's (2-sided) test to determine level of significance.

\section{Results and Discussion}

Figure 1 depicts rapid increases in the extracellular concentration of glutathione following administration of each of the three drugs. A significant high concentration of the tripeptide continued throughout the first 100 min following single KA injection (Figure 1(a)) while the increase remains high throughout the whole experiment after continuous NMDA perfusion (Figure 1(b)). Only two fractions (40 min) following bicuculline perfusion contained significantly elevated glutathione concentrations (Figure 1(c)).

Although results without acivicin addition (Figures 1(a)-(c)) reveal less concentration of glutathione than with acivicin addition (Figure 2(a)), there was still no difference in the pattern of glutathione elevation between the groups, with exception of that under KA treatment the glutathione concentration was significantly high during the last fraction, i.e. at 120 min (Figure 2(a) vs. Figure 1(a)).

As well as showing the glutathione concentration under acivicin effect, Figure 2 summarizes also the extracellular concentrations of taurine and PEA under drug treatments. While a fast increase from baseline (dashed horizontal lines) in taurine and PEA following NMDA perfusion is obvious, a relatively delayed taurine and

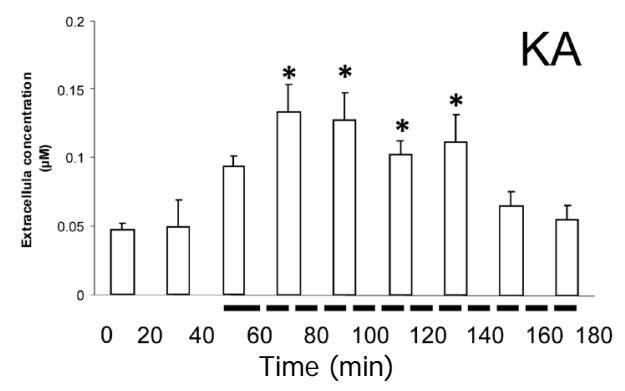

(a)

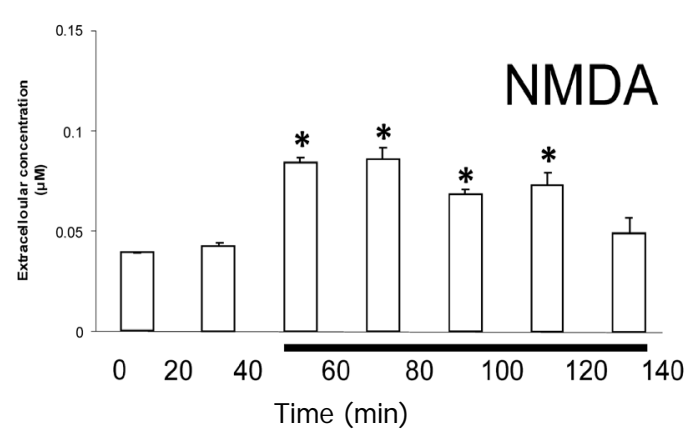

(b)

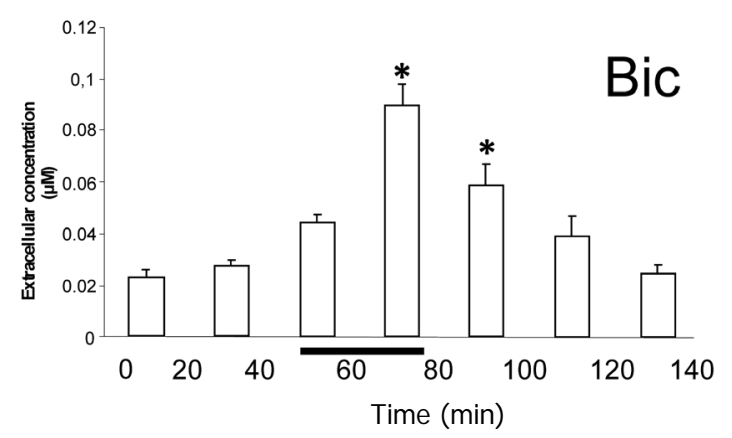

(c)

Figure 1. Changes of total extracellular glutathione following KA, NMDA, and bicuculline (Bic) in absence of acivicin. The hippocampus was perfused with Krebs-Ringer solution for $40 \mathrm{~min}$ followed by administration of (a) KA ( $n=5$ ); (b) NMDA $(n=4)$, or (c) Bic $(n=4)$. Horizontal bars indicate periods of the drug administration. The rationale for two fractions bicuculline perfusion is that such dose has been shown to be sufficient to induce seizure activity [28]. Results are expressed as mean of the concentration of total glutathione in one hippocampus wherein acivicin was not added. ${ }^{*} P<0.05$ when comparing the drug-mediated efflux with the basal efflux. 


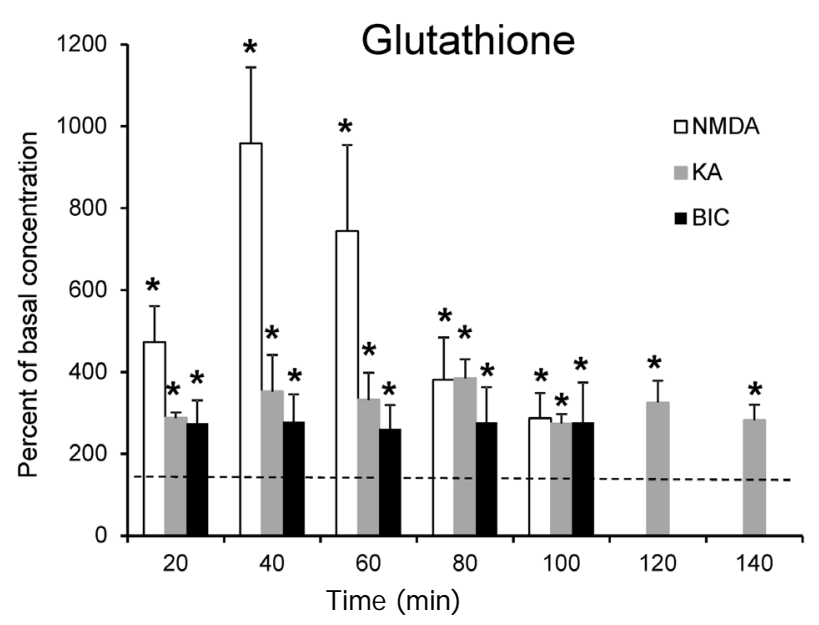

(a)

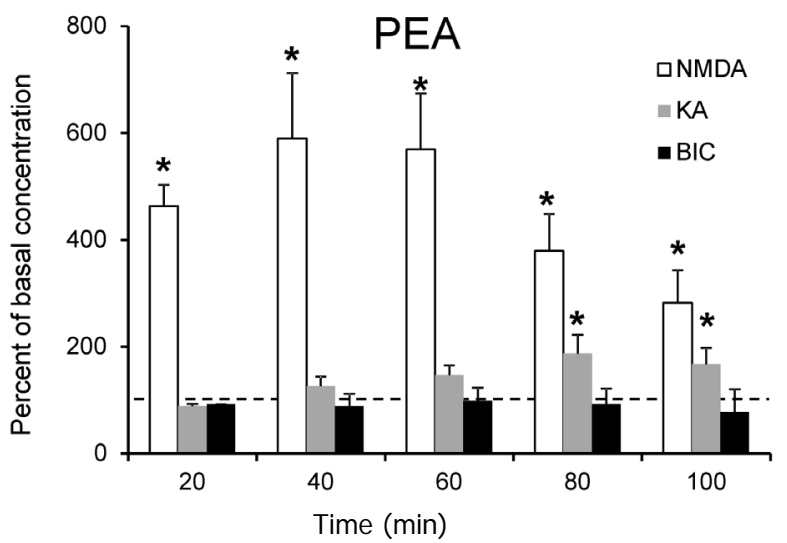

(b)

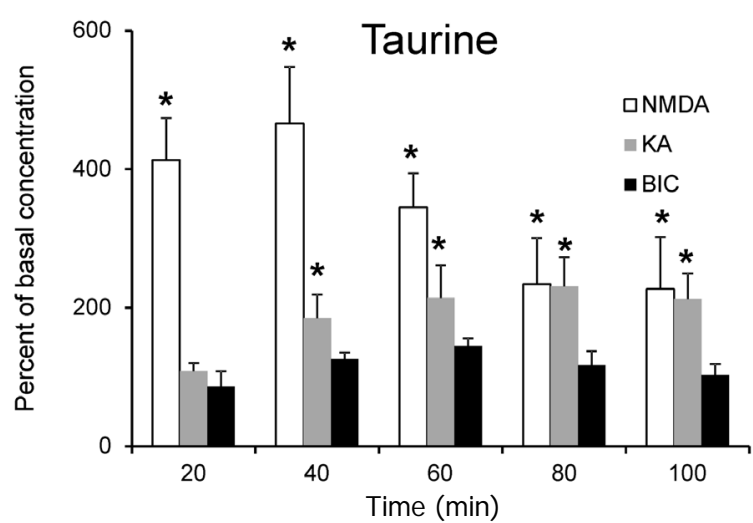

(c)

Figure 2. Changes of total glutathione (a); PEA (b); and taurine (c) following KA ( $n=5)$, NMDA ( $n=4)$, and bicuculline (Bic; $n=4$ ) administration in the hippocampal side wherein acivicin was added (the periods of drug administration as in Figure 1). Values are expressed as percent of change of basal concentration estimated as the average of two fractions of acivicin application referred to baseline values (dashed line). ${ }^{*} P<0.05$.

markedly delayed PEA increase accompany KA administration (Figure 2(b) and Figure 2(c)). There was no difference between perfusates with or without acivicin concerning the concentration of taurine and PEA (data not shown). However, bicuculline does not show any effect on either amino acid (Figure 2(b) and Figure 2(c)). Concentrations of aspartate, glycine or glutamine were not influenced by either drug (data not shown).

The extracellular concentration of glutamate is significantly high 60 min following KA administration. This high concentration continues throughout the experiment (for extra $80 \mathrm{~min}$; Figure 3(a)). This response is not shown with either of other drugs (Figure 3(a)). It is quite obvious that the baseline values of glutamate are different as seen in the first 20-min fraction in which glutamate is too high in bicuculline experiments. This difference could be presumed to be due to different times, at which experiments of each group were conducted, which might likely associate with different rat age, weight as well as individual variation.

Furthermore, addition of acivicin did not change the extracellular glutamate indicating that the increase in glutamate is not due to hydrolysis of glutathione (Figure 3(b)) (cf. Ref. [23]).

\section{Discussion}

The principal results of these experiments are in accord with our previous observations in vitro [19] [20]. However, although there is accumulating evidence indicates that hippocampal oxidative insults might be involved in KA-induced neurotoxicity in vivo [24] and in vitro [25] and seizure activity coincides with enhanced oxidative 


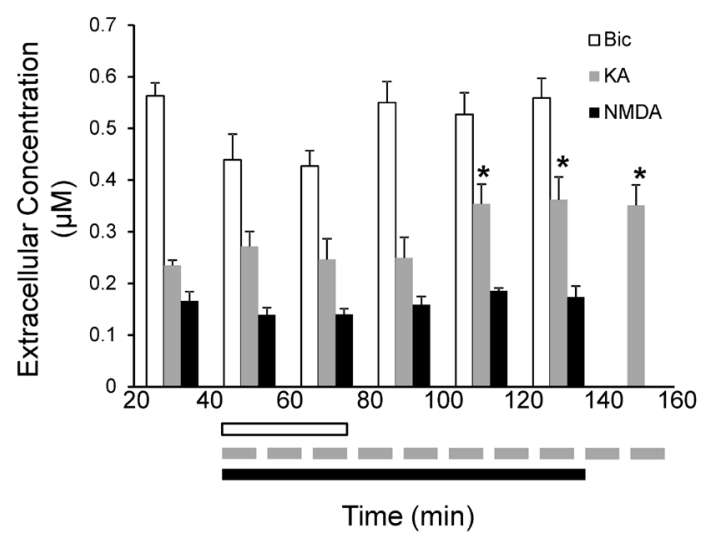

(a)

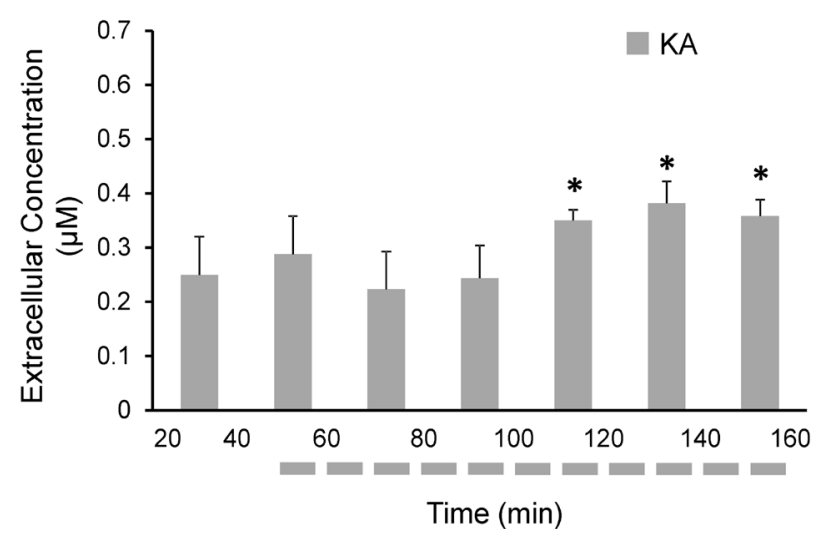

(b)

Figure 3. KA $(n=5)$, but not bicuculline (Bic; $n=4)$ or NMDA $(n=4)$, caused a delayed increase in the extracellular concentration of glutamate either with (a) or without (b) the addition of acivicin. The comparison is made between each fraction and the first fraction representing an average of the last three baseline fractions. Horizontal bars in (a) indicate the drug applications which are only with bicuculline (black bar) perfused intracerebrally for only two fractions; (b) Depicts only the effect of KA (horizontal dashed bar) on glutamate concentration. ${ }^{*} P<0.05$.

stress [10] [24], the stereotaxic strain and the continuous anesthesia might mask the appearance of motor activity though they would not necessarily prevent the electroencephalographic activity [26] or the appearance of facial motor activity as observed in the present study. Similarly, it is well known that g-aminobutyric acid (GABA) modulates the excitability of pyramidal and granule neurons in the hippocampus [27] and both, blockade of $\mathrm{GABA}_{\mathrm{A}}$ receptors by bicuculline [28] and activation of the NMDA receptors [29] are commonly used as seizure models.

KA administered systemically induced continuous high glutathione concentrations evident in the second fraction. This result has a temporal pattern similar to that shown in acute hippocampal slice preparations [19], suggesting that the drug quickly infiltrates the brain. Given that the net efflux of oxidized glutathione has been shown to be higher during basal conditions than following NMDA perfusion [19], it is plausible that the increase in extracellular glutathione represents majorly a reduced form of the tripeptide.

The NMDA-induced increase in extracellular glutathione levels also exhibits a temporal pattern similar to that seen in vitro preparations [19] [20] [30]. However, despite continuous NMDA perfusion, glutathione concentration returned back to its baseline values 100 min after the perfusion (Figure 1(b)). Although this relatively sustained increase in concentration compared to transient increase induced by drug puffs in vitro [19] [20], the return to baseline values may indicate that glutathione efflux is a transient step during insult conditions. This is compatible with insult induced by transient intrahippocampal bicuculline perfusion (Figure 1(c)).

Although the significance of glutathione efflux to brain function is not very clear, the tripeptide may furnish the immediate extracellular milieu of cells against oxidants, which are associated with excitotoxicity induced by glutamate analogues [12], disinhibition of GABAergic pathway or associated with neuropathological disorders such as stroke and seizures [31] [32].

Regardless the sources of glutathione efflux [19] [20] [33], the transient characteristic of the increase in extracellular glutathione concentration following different administration regimes (systemic and intrahippocampal), different drugs, and different intervals (continuous and transient) gives a clue that it might be a putative early biomarker for the development and/or severity of several neuropathological conditions. For example, enhanced efflux of the oxidized glutathione from neurons in vitro was observed to precede cell death in a toxicity model involving oxidative stress [34]. Furthermore, the significant increase in the extracellular concentration of glutathione 40 min following KA injection (Figure 1(a)) is compatible with the significant value of behavioral score of epileptic seizure induced by the drug. This score reaches maximum value at 100 min following injection [33].

An increase in the extracellular concentrations of taurine is also shown to accompany glutathione. Although the effect of KA and NMDA on taurine efflux shown in the present work is in line with previous reports [20] [30], the lack of such effect by bicuculline is surprising (see below). 
Beside its roles as osmoregulator and antioxidant, taurine has a neuromodulatory effect (for references, see Introduction) against glutamate neurotoxicity [35]. The time point at which maximal taurine release is observed following NMDA perfusion is compatible with in vitro studies [19] [20], as with various excitotoxic conditions [16] [17]. Similar effect to in vitro [19] and in vivo [36] drug application is induced by KA (Figure 2(c)). Regarding the lack of bicuculline's effect on taurine release, it is known that basal taurine release is potentiated by GABA transmission, but not influenced by the $\mathrm{GABA}_{\mathrm{A}}$ receptor antagonist bicuculline [37], indicating the plausibility of other GABA receptors to mediate taurine release.

Although the fast increase in the extracellular concentration of PEA induced by NMDA perfusion is incompatible with findings shown in vitro [19] [20] and in vivo [18], the delayed release following KA injection is similar to that shown in vitro [19] and in vivo [36] preparations. It is likely that the increase in PEA concentration originates from the intracellular free pool rather than from phospholipid breakdown [16] [30] [38].

The delayed increase in glutamate concentration following KA injection seems also incompatible to the findings shown in vitro preparation [30], which revealed either no effect or even a decrease in the net efflux of glutamate [19]. Although it is not very clear why KA injection has different effect on the extracellular glutamate concentration compared to KA puff in vitro, despite the parallel time point at which glutamate concentration was analyzed, i.e. 80 - 120 min (Ref. [30]) vs. Figure 3(a), Figure 3(b), likely in vivo experiments have distinguished characteristics that diverge from in vitro organotypic preparation [33], such as the involvement of activation of the hypothalamic-pituitary-adrenal axis in the mechanisms of KA systemic injection [39]. Furthermore, it is unlikely that the extracellular pool of glutamate following KA injection serves in glutathione synthesis as at 120 min following KA injection the glutathione concentration returned back to baseline values (Figure 1(a)) whereas glutamate was significantly high (Figure 3(a), Figure 3(b)). It can be suggested that the KA-evoked glutamate increase in the extracellular concentration, preceded by high glutathione concentration, may be associated with triggered seizure activity [40], constituting a hallmark in vivo. The absence of an effect on the concentration of other amino acids (e.g. glutamine) is in line with the suggestion that the elevated glutamate is not due to ischemic effect or neuronal damage ( $c f$. Ref. [16]). The lack of effect of either bicuculline or NMDA on glutamate concentration could be relied on the relatively short time points of monitoring or to other unknown factors.

The relevance of these findings to induction of seizure can be described in the following tentative scenario:

The initial stages of KA-induced seizures, which are restricted to limbic structures, represent a model of propagation of focal, temporal lobe seizures [41]. This is in analogy with local administration of other convulsants such as NMDA [29] [42] and bicuculline [28] [43]. Consequently, the induced increase in the extracellular glutathione concentrations caused by the drugs used in this work raises the issue whether extracellular glutathione serves protective [44] or harmful [45] functions similar to its intracellular pool. However, the transient property of the increase rules out the likelihood of harmful effect, preferring the suggestion of a protective response (cf. [44]). It remains though possible that extracellular glutathione is excitotoxic when the increase was high [46] and/or associated with an increase in the glutamate concentration [47] [48], observed to follow KA administration. Taurine is a modulator of neuronal excitability and may therefore serve as endogenous anticonvulsant [14] [49]. This implies that flooding of the interstitial space by taurine might constitute an autoprotective mechanism against toxicity induced by KA [50], NMDA [51], and bicuculline [52]. On other hand, the immediate increase in extracellular levels of the lipid component, PEA, following local perfusion of NMDA may reflect membrane recycling and signaling (e.g. [53]); whereas the delayed increase following systemic KA administration may reflect the slow pharmacokinetics of the drug. This is likely the case because the temporal profile of PEA was nearly close to glutathione, when acivicin was omitted (Figure 1(a) vs. Figure 2(b)). It remains though enigmatic that bicuculline did not induce an effect on the extracellular concentration of PEA despite the mechanistic association between PEA and taurine is well-documented [54] [55].

Notably, it is still cautious to conclude whether these changes in the extracellular concentrations of amino acids and glutathione are generally due to the inducing agents themselves, to the shift from normal into ictal discharges [56], or they are solely connected with the masked behavioral seizures. For elucidating these issues, further studies should focus on the temporal relationship of these parametric changes and electrophysiological activity on one hand, and on the relationship between these changes and behavioral activity, on the other hand.

Altogether, it can be presumed that the changes in the amino acids and glutathione may constitute early transient biomarkers for seizure induction although a mechanistic correlation between them and seizure propagation is hardly to be imagined at this stage of study. In the light of these preliminary results, a tentative pictorial model is described in Figure 4. 


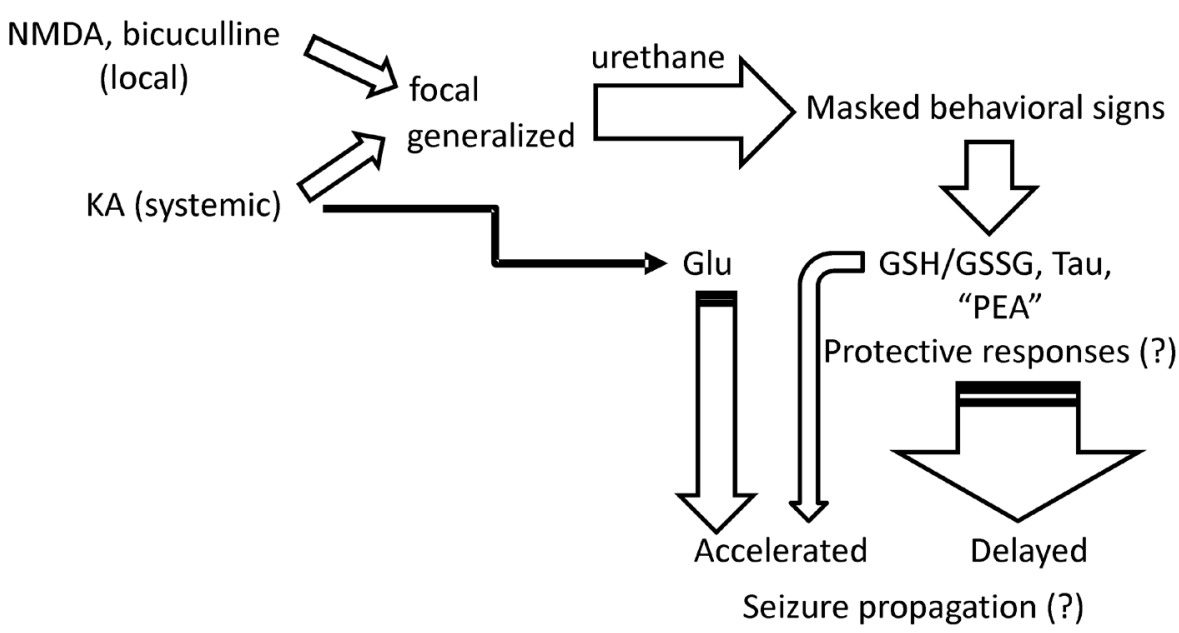

Figure 4. Schematic illustration describing a working hypothesis based on the current findings. While anesthetic and stereotaxic approaches masked behavioral signs associated with seizure propagation, biochemical changes were obvious. This could be inferred from the glutamate (Glu) increase following systemic KA administration. However, despite the agents exert seizure activity via different mechanisms of action, and despite they were given via different routes; they share the characteristic on glutathione (GSH/GSSG) and taurine (Tau) extracellular increase. The latter parameters are plausibly indices for the predisposition of seizure activity in the hippocampus by representing a protective response in trial to ameliorate and delay seizure propagation. In contrast to other agents, the KA-mediated high extracellular Glu concentration may act synergistically with glutathione to accelerate behavioral and/or electrical seizure activity. However, the illustration is simplistic as it does not take in account the hippocampal regional differences which are well known to have different stage contribution during seizure induction mechanisms.

\section{Conclusion}

Although glutathione has generally been shown to have implication in both long-standing, chronic neurodegenerative disorders [3] [57] as well as aging [58], and acute conditions such as cerebral ischemia [59], the pharmacological agents in the present work are known to be excitotoxic as well as commonly used as convulsing chemicals. Although the present report is in principle descriptive, as several other issues such as the temporal correlation between the amino acid parameter changes and cell death, the source for the extracellular glutathione pool, the consequence, if there is any, of the elevated peptide and amino acids as well as an mechanistic explanation for the shown changes remain to be investigated, it can be proposed that the parameters observed here represent early neurochemical hallmarks for a wide-spread neurological disorder, including epileptic and/or epileptogenic events. Thus, while glutamate release and/or uptake inhibition are antecedent to the occurrence of convulsions, glutathione, taurine, and to less extent PEA may constitute the first biomarkers for excitotoxicity and seizure activity. The application of the method to humans has been introduced, since long time in clinical settings [60] [61]. If the proposal were true, both diagnostic and therapeutic strategies can take the advantage of the appearance of these markers, which, for example, may accelerate diagnostic procedures and improve the outcome of therapeutics within a critical period.

\section{Acknowledgements}

I am most grateful for the careful reading and instructive comments on earlier drafts of this essay by Drs. Mats Sandberg and Paul Gold. This work was supported by the foundations of Handlanden Hjalmar Svensson, Wilhelm och Martina Lundgren, and Sigurd och Elsa Goljes Minne; the Swedish Medical Society and the Gothenburg Medical Society.

\section{References}

[1] Forman, H.J., Zhang, H. and Rinna, A. (2009) Glutathione: Overview of Its Protective Roles, Measurement, and Biosynthesis. Molecular Aspects of Medicine, 30, 1-12. http://dx.doi.org/10.1016/j.mam.2008.08.006

[2] Slivka, A., Spina, M.B. and Cohen, G. (1987) Reduced and Oxidized Glutathione in Human and Monkey Brain. Neuroscience Letters, 74, 112-118. http://dx.doi.org/10.1016/0304-3940(87)90061-9 
[3] Chinta, S.J., Kumar, M.J., Hsu, M., Rajagopalan, S., Kaur, D., et al. (2007) Inducible Alterations of Glutathione Levels in Adult Dopaminergic Midbrain Neurons Result in Nigrostriatal Degeneration. Journal of Neuroscience, 27, 1399714006. http://dx.doi.org/10.1523/JNEUROSCI.3885-07.2007

[4] Oliveira, A.A., Almeida, J.P.C., Freitas, R.M., Nascimento, V.S., Aguiar, L.M.V., et al. (2007) Effects of Levetiracetam in Peroxidation Level, Nitrite-Nitrate Formation and Antioxidant Enzymatic Activity in Mice Brain after Pilocarpine-Induced Seizures. Cellular and Molecular Neurobiology, 27, 395-406. http://dx.doi.org/10.1007/s10571-006-9132-y

[5] Köhr, G., Eckardt, S., Lüddens, H., Monyer, H. and Seeburg, P.H. (1994) NMDA Receptor Channels: Subunit-Specific Potentiation by Reducing Agents. Neuron, 12, 1031-1040. http://dx.doi.org/10.1016/0896-6273(94)90311-5

[6] Bodhinathan, K., Kumar, A. and Foster, T.C. (2010) Intracellular Redox State Alters NMDA Receptor Response during Aging through $\mathrm{Ca}^{2+} /$ Calmodulin-Dependent Protein Kinase II. The Journal of Neuroscience, 30, 1914-1924. http://dx.doi.org/10.1523/JNEUROSCI.5485-09.2010

[7] Ogita, K., Kitago, T., Nakamuta, H., Fukuda, Y., Koida, M., et al. (1986) Glutathione-Induced Inhibition of Na ${ }^{+}$ Independent and -Dependent Bindings of L- $\left[{ }^{3} \mathrm{H}\right]$ Glutamate in Rat Brain. Life Sciences, 39, 2411-2418. http://dx.doi.org/10.1016/0024-3205(86)90482-0

[8] Patten, A.R., Brocardo, P.S., Sakiyama, C., Wortman, R.C., Noonan, A., et al. (2013) Impairments in Hippocampal Synaptic Plasticity Following Prenatal Ethanol Exposure Are Dependent on Glutathione Levels. Hippocampus, 23, 1463-1475. http://dx.doi.org/10.1002/hipo.22199

[9] Robillard, J.M., Gordon, G.R., Choi, H.B., Christie, B.R. and MacVicar, B.A. (2011) Glutathione Restores the Mechanism of Synaptic Plasticity of the Adult. PLOS ONE, 6, e20676. http://dx.doi.org/10.1371/journal.pone.0020676

[10] Bruce, A.J. and Baudry, M. (1995) Oxygen Free Radicals in Rat Limbic Structures after Kainite-Induced Seizures. Free Radical Biology and Medicine, 18, 993-1002. http://dx.doi.org/10.1016/0891-5849(94)00218-9

[11] Freitas, R.M., Vasconcelos, S.M.M., Souza, F.C.F., Viana, G.S.B. and Fonteles, M.M.F. (2005) Oxidative Stress in the Hippocampus after Pilocarpine-Induced Status Epilepticus in Wistar Rats. FEBS Journal, 272, 1307-1312. http://dx.doi.org/10.1111/j.1742-4658.2004.04537.x

[12] Dugan, L.L., Sensl, S.L., Canzoniero, L.M.T., Handran, S.D., Rothman, S.M., et al. (1995) Mitochondrial Production of Reactive Oxygen Species in Cortical Neurons Following Exposure to N-methyl-D-Aspartate. Journal of Neuroscience, 15, 6377-6388.

[13] Wade, J.V., Olson, J.P., Samson, F.E., Nelson, S.R. and Pazdernik, T.L. (1988) A Possible Role for Taurine in Osmoregulation within the Brain. Journal of Neurochemistry, 51, 740-745. http://dx.doi.org/10.1111/j.1471-4159.1988.tb01807.x

[14] El-Abhar, H.S. and El Gawad, H.M. (2003) Modulation of Cortical Nitric Oxide Synthase, Glutamate, and Redox State by Nifedipine and Taurine in PTZ-Kindled Mice. Epilepsia, 44, 276-281. http://dx.doi.org/10.1046/j.1528-1157.2003.22302.x

[15] Huxtable, R.J. (1992) Physiological Actions of Taurine. Physiological Reviews, 72, 101-163.

[16] Hagberg, H., Lehmann, A., Sandberg, M., Nyström, B., Jacobson, I., et al. (1985) Ischemia-Induced Shift of Inhibitory and Excitatory Amino Acids from Intra- to Extracellular Compartments. Journal of Cerebral Blood Flow \& Metabolism, 5, 413-419. http://dx.doi.org/10.1038/jcbfm.1985.56

[17] Sandberg, M., Butcher, S.P. and Hagberg, H. (1986) Extracellular Overflow of Neuroactive Amino Acids during Severe Insulin-Induced Hypoglycemia: In Vivo Dialysis of the Rat Hippocampus. Journal of Neurochemistry, 47, 178184. http://dx.doi.org/10.1111/j.1471-4159.1986.tb02847.x

[18] Lo, E.H., Bosque-Hamilton, P. and Meng, W. (1998) Inhibition of Poly(ADP-Ribose) Polymerase: Reduction of Ischemic Injury and Attenuation of N-methyl-D-Aspartate-Induced Neurotransmitter Dysregulation. Stroke, 29, 830836. http://dx.doi.org/10.1161/01.STR.29.4.830

[19] Wallin, C., Weber, S.G. and Sandberg, M. (1999) Glutathione Efflux Induced by NMDA and Kainate: Implications in Neurotoxicity? Journal of Neurochemistry, 73, 1566-1572. http://dx.doi.org/10.1046/j.1471-4159.1999.0731566.x

[20] Wallin, C., Abbas, A.K., Tranberg, M., Weber, S.G., Wigström, H. and Sandberg, M. (2003) Searching for Mechanisms of N-Methyl-D-Aspartate-Induced Glutathione Efflux in Organotypic Hippocampal Cultures. Neurochemical Research, 28, 281-291. http://dx.doi.org/10.1023/A:1022381318126

[21] Lehmann, A., Isacsson, H. and Hamberger, A. (1983) Effects of in Vivo Administration of Kainic Acid on the Extracellular Amino Acid Pool in the Rabbit Hippocampus. Journal of Neurochemistry, 40, 1314-1320. http://dx.doi.org/10.1111/j.1471-4159.1983.tb13572.x

[22] Keillor, J.W., Castonguay, R. and Lherbet, C. (2005) Gamma-Glutamyl Transpeptidase Substrate Specificity and Catalytic Mechanism. Methods in Enzymology, 401, 449-467. http://dx.doi.org/10.1016/S0076-6879(05)01027-X

[23] Li, X., Wallin, C., Weber, S.G. and Sandberg, M. (1999) Net Efflux of Cysteine, Glutathione and Related Metabolites 
from Rat Hippocampal Slices during Oxygen/Glucose Deprivation: Dependence on Gamma-Glutamyl Transpeptidase. Brain Research, 815, 81-88. http://dx.doi.org/10.1016/S0006-8993(98)01097-X

[24] Kim, H.C., Jhoo, W.K., Kim, W.K., Suh, J.H., Shin, E.J., et al. (2000) An Immunocytochemical Study of Mitochondrial Manganese-Superoxide Dismutase in the Rat Hippocampus after Kainite Administration. Neuroscience Letters, 281, 65-68. http://dx.doi.org/10.1016/S0304-3940(99)00969-6

[25] Shih, Y.H., Chein, Y.C., Wang, J.Y. and Fu, Y.S. (2004) Ursolic Acid Protects Hippocampal Neurons against Kainite-Induced Excitotoxicity in Rats. Neuroscience Letters, 362, 136-140. http://dx.doi.org/10.1016/j.neulet.2004.03.011

[26] Saito, T., Sakamoto, K., Koizumi, K. and Stewart, M. (2006) Repeatable Focal Seizure Suppression: A Rat Preparation to Study Consequences of Seizure Activity Based on Urethane Anesthesia and Reversible Carotid Artery Occlusion. Journal of Neuroscience Methods, 155, 241-250. http://dx.doi.org/10.1016/j.jneumeth.2006.01.021

[27] Fedele, E., Varnier, G. and Paiteri, M. (1997) In Vivo Microdialysis Study of GABA And GABA $_{B}$ Receptors Modulating the Glutamate Receptor/NO/Cyclic GMP Pathway in the Rat Hippocampus. Neuropharmacology, 36, 1405 1415. http://dx.doi.org/10.1016/S0028-3908(97)00113-5

[28] Anschel, D.J., Ortega, E. and Fisher, R.S. (2004) Diazepam Prophylaxis for Bicuculline-Induced Seizures: A Rat Dose-Response Model. Neuroscience Letters, 356, 66-68. http://dx.doi.org/10.1016/j.neulet.2003.10.082

[29] Engel Jr., J. (1992) Experimental Animal Models of Epilepsy: Classification and Relevance to Human Epileptic Phenomena. Epilepsy Research. Supplement, 8, 9-20.

[30] Tranberg, M., Stridh, M.H., Guy, Y., Jilderos, B., Wigström, H., Weber, S.G. and Sandberg, M. (2004) NMDA-Receptor Mediated Efflux of $N$-Acetylaspartate: Physiological and/or Pathological Importance? Neurochemistry International, 45, 1195-1204. http://dx.doi.org/10.1016/j.neuint.2004.06.005

[31] de Freitas, R.M. (2010) Lipoic Acid Alters $\delta$-Aminolevulinic Dehydratase, Glutathione Peroxidase and Na+,K+-ATPase Activities and Glutathione-Reduced Levels in Rat Hippocampus after Pilocarpine-Induced Seizures. Cellular and Molecular Neurobiology, 30, 381-387. http://dx.doi.org/10.1007/s10571-009-9460-9

[32] Li, Z.X., Yu, H.M. and Jiang, K.W. (2013) Tonic GABA Inhibition in Hippocampal Dentate Granule Cells: Its Regulation and Function in Temporal Lobe Epilepsies. Acta Physiologica, 209, 199-211. http://dx.doi.org/10.1111/apha.12148

[33] Eyo, U.B., Peng, J., Swiatkowski, P., Mukherjee, A., Bispo, A. and Wu, L.J. (2014) Neuronal Hyperactivity Recruits Microglial Processes via Neuronal NMDA Receptors and Microglial P2Y12 Receptors after Status Epilepticus. Journal of Neuroscience, 34, 10528-10540. http://dx.doi.org/10.1523/JNEUROSCI.0416-14.2014

[34] Zeevalk, G.D., Bernard, L.P., Sinha, C., Ehrhart, J. and Nicklas, W.J. (1998) Excitotoxicity and Oxidative Stress during Inhibition of Energy Metabolism. Developmental Neuroscience, 20, 444-453. http://dx.doi.org/10.1159/000017342

[35] Wu, J.Y., Wu, H., Jin, Y., Wie, J., Sha, D., et al. (2009) Mechanism of Neuroprotective Function of Taurine. Advances in Experimental Medicine and Biology, 643, 169-179. http://dx.doi.org/10.1007/978-0-387-75681-3_17

[36] Lehmann, A., Hagberg, H., Jacobson, I. and Hamberger, A. (1985) Effects of Status Epilepticus on Extracellular Amino Acids in the Hippocampus. Brain Research, 359, 147-151. http://dx.doi.org/10.1016/0006-8993(85)91422-2

[37] Saransaari, P. and Oja, S.S. (2000) Taurine Release Modified by GABAergic Agents in Hippocampal Slices from Adult and Developing Mice. Amino Acids, 18, 17-30. http://dx.doi.org/10.1007/s007260050002

[38] Gasull, T., Sarri, E., DeGregorio-Rocasolano, N. and Trullas, R. (2003) NMDA Receptor Overactivation Inhibits Phospholipid Synthesis by Decreasing Choline-Ethanolamine Phosphotransferase Activity. Journal of Neuroscience, 23, 4100-4107.

[39] Stein, B.A. and Sapolsky, R.M. (1988) Chemical Adrenalectomy Reduces Hippocampal Damage Induced by Kainic Acid. Brain Research, 473, 175-180. http://dx.doi.org/10.1016/0006-8993(88)90332-0

[40] Cavus, I., Kasoff, W.S., Cassaday, M.P., Jacob, R., Gueorguieva, R., et al. (2005) Extracellular Metabolites in the Cortex and Hippocampus of Epileptic Patients. Annals of Neurology, 57, 226-235. http://dx.doi.org/10.1002/ana.20380

[41] Lévesque, M., Avoli, M. and Bernard, C. (2015) Animal Models of Temporal Lobe Epilepsy Following Systemic Chemoconvulsant Administration. Journal of Neuroscience Methods (In Press). http://dx.doi.org/10.1016/j.jneumeth.2015.03.009

[42] Ludvig, N. and Tang, H.M. (2000) Cellular Electrophysiological Changes in the Hippocampus of Freely Behaving Rats during Local Microdialysis with Epileptogenic Concentration of N-Methyl-D-Aspartate. Brain Research Bulletin, 51, 233-240. http://dx.doi.org/10.1016/S0361-9230(99)00223-3

[43] Stein, A.G., Eder, H.G., Blum, D.E., Drachev, A. and Fisher, R.S. (2000) An Automated Drug Delivery System for Focal Epilepsy. Epilepsy Research, 39, 103-114. http://dx.doi.org/10.1016/S0920-1211(99)00107-2

[44] Jiang, D., Akopian, G., Ho, Y.S., Walsh, J.P. and Andersen, J.K. (2000) Chronic Brain Oxidation in a Glutathione Peroxidase Knockout Mouse Model Results in Increased Resistance to Induced Epileptic Seizures. Experimental Neu- 
rology, 164, 257-268. http://dx.doi.org/10.1006/exnr.2000.7431

[45] Fico, A., Manganelli, G., Cigliano, L., Bergamo, P., Abrescia, P., et al. (2008) 2-deoxy-d-Ribose Induces Apoptosis by Inhibiting the Synthesis and Increasing the Efflux of Glutathione. Free Radical Biology and Medicine, 45, $211-217$. http://dx.doi.org/10.1016/j.freeradbiomed.2008.04.017

[46] Regan, R.F. and Guo, Y.P. (1999) Potentiation of Excitotoxic Injury by High Concentrations of Extracellular Reduced Glutathione. Neuroscience, 91, 463-470. http://dx.doi.org/10.1016/S0306-4522(98)00597-1

[47] Aroniadou-Anderjaska, V., Pidoplichko, V.I., Figueiredo, T.H., Almeida-Suhett, C.P., Prager, E.M. and Braga, M.F.M. (2012) Presynaptic Facilitation of Glutamate Release in the Basolateral Amygdala: A Mechanism for the Anxiogenic and Seizurogenic Function of GluK1 Receptors. Neuroscience, 221, 157-169. http://dx.doi.org/10.1016/j.neuroscience.2012.07.006

[48] Sierra-Paredes, G., Loureiro, A.I., Wright, L.C., Sierra-Marcuo, G. and Soares-da-Silva, P. (2014) Effects of Eslicarbazepine Acetate on Acute and Chronic Latrunculin A-Induced Seizures and Extracellular Amino Acid Levels in the Mouse Hippocampus. BMC Neuroscience, 15, 134. http://dx.doi.org/10.1186/s12868-014-0134-2

[49] Oja, S.S. and Saransaari, P. (2013) Regulation of Taurine Release in the Hippocampus of Developing and Adult Mice. Advances in Experimental Medicine and Biology, 775, 135-143. http://dx.doi.org/10.1007/978-1-4614-6130-2_11

[50] Junyent, E., Utrera, J., Romero, R., Pallas, M., Camins, A., Duque, D. and Auladell, C. (2009) Prevention of Epilepsy by Taurine Treatments in Mice Experimental Model. Journal of Neuroscience Research, 87, 1500-1508. http://dx.doi.org/10.1002/jnr.21950

[51] Durelli, L. and Mutani, R. (1983) The Current Status of Taurine in Epilepsy. Clinical Neuropharmacology, 6, 37-48. http://dx.doi.org/10.1097/00002826-198303000-00004

[52] Dzirkale, Z., Pupure, J., Rumaks, J., Svirskis, S., Vanina, M., et al. (2011) Comparative Study of Taurine and Tauropyrone: GABA Receptor Binding, Mitochondrial Processes and Behavior. Journal of Pharmacy and Pharmacology, 63, 230-237. http://dx.doi.org/10.1111/j.2042-7158.2010.01204.x

[53] Seu, K.J., Cambrea, L.R., Everly, R.M. and Hovis, J.S. (2006) Influence of Lipid Chemistry on Membrane Fluidity: Tail and Headgroup Interactions. Biophysical Journal, 91, 3727-3735. http://dx.doi.org/10.1529/biophysj.106.084590

[54] Lehmann, A. and Hamberger, A. (1984) A Possible Interrelationship between Extracellular Taurine and Phosphoethanolamine in the Hippocampus. Journal of Neurochemistry, 42, 1286-1290. http://dx.doi.org/10.1111/j.1471-4159.1984.tb02785.x

[55] Huxtable, R.J., Crosswell, S. and Parker, D. (1989) Phospholipid Composition and Taurine Content of Synaptosomes in Developing Rat Brain. Neurochemistry International, 15, 233-238. http://dx.doi.org/10.1016/0197-0186(89)90106-X

[56] Jirsa, V.K., Stacey, W.C., Quilichini, P.P., Ivanov, A.I. and Bernard, C. (2014) On the Nature of Seizure Dynamics. Brain, 137, 2210-2230. http://dx.doi.org/10.1093/brain/awu133

[57] Klein, J.A. and Ackerman, S.L. (2003) Oxidative Stress, Cell Cycle, and Neurodegeneration. Journal of Clinical Investigation, 111, 785-793. http://dx.doi.org/10.1172/JCI200318182

[58] Currais, A. and Maher, P. (2013) Functional Consequences of Age-Dependent Changes in Glutathione Status in the Brain. Antioxidants \& Redox Signaling, 19, 813-822. http://dx.doi.org/10.1089/ars.2012.4996

[59] Bragin, D.E., Zhou, B., Ramamoorthy, P., Müller, W.S., Connor, J.A. and Shi, H. (2010) Differential Changes of Glutathione Levels in Astrocytes and Neurons in Ischemic Brains by Two-Photon Imaging. Journal of Cerebral Blood Flow \& Metabolism, 30, 734-738. http://dx.doi.org/10.1038/jcbfm.2010.9

[60] Meyerson, B.A., Linderoth, B., Karlsson, H. and Ungerstedt, U. (1990) Microdialysis in the Human Brain: Extracellular Measurements in the Thalamus of Parkinsonian Patients. Life Sciences, 46, 301-308. http://dx.doi.org/10.1016/0024-3205(90)90037-R

[61] Hillered, L., Persson, L., Pontén, U. and Ungerstedt, U. (1990) Neurometabolic Monitoring of the Ischaemic Human Brain Using Microdialysis. Acta Neurochirurgica, 102, 91-97. http://dx.doi.org/10.1007/BF01405420

\section{Abbreviations}

GGT, Gamma-Glutamyl Transpeptidase;

KA, Kainic Acid;

PEA, Phosphoethanolamine. 